\title{
Azulejos pintados toledanos: colección de la Casa y Museo de El Greco
}

\author{
María luisa Menéndez Robles *
}

\section{INTRODUCCION}

Se considera como azulejo en sentido estricto a una pieza de barro vidriado de forma cuadrada o rectangular, destinada a revestimientos arquitectónicos. Es esta su finalidad principal aunque no la única sobre todo desde la implantación del azulejo plano pintado para cubrir amplias superficies como si se tratara de cuadros o tapices. Muy a menudo se forran con estas piezas cerámicas pavimentos, techos, envigados y cubiertas en exterior, pero van a ser los muros el espacio predilecto para chapar. Es justamente esta preferencia la que personaliza, por lo que al uso se refiere, al azulejo pintado peninsular frente a su homónimo italiano. Las características de la superficie recubierta van a incidir sobre la selección de motivos que se organizarán en grandes paneles murarios desarrollados de manera continuada. La temática del azulejo que reviste paramentos gira en torno a lo que se denomina azulejos de composición en los que se representa un asunto o motivo puntual a cuyo realce contribuye el resto, o bien más frecuentemente, se opta por repetir un motivo contenido íntegramente en cada azulejo, que además posee parte de otro común con la contigua. Se lográ así con el empleo de módulos repetitivos, hacer asociaciones en cualquier dirección, según las posibilidades del espacio disponible, de ahí el enorme éxito de la fórmula.

\footnotetext{
* Casa y Museo del Greco
} 
La parte del muro o zócalo de azulejos se divide en áreas jerarquizadas que recibirán distinto tratamiento ornamental según su importancia. La más relevante es la franja central en la que va a desarrollarse el panel principal donde se puede escenificar más o menos ampliamente un tema, o repetir indefinidamente un mismo motivo generalmente vegetal o por último combinar ambas fórmulas. El conjunto se envuelve con sucesivas orlas o cenefas de motivos muy variados, bien representados en la colección de azulejos planos pintados polícromos de la Casa y Museo del Greco, a la que más adelante nos referiremos.

La costumbre de forrar el muro con azulejos no responde únicamente a razones de carácter estético, hay también un componente práctico que generalmente se ha olvidado en los estudios sobre el tema. Se protegen de este modo los arrimaderos, alfeizares de ventanas, escalones y cualquier otra superficie, de los desgastes que pueda sufrir, mediante el empleo de un material resistente, fácilmente renovable y barato. Hay además otro problema que se aminora con esta solución, el de la existencia de humedades, casi una constante en los edificios antiguos donde el ascenso por capilaridad a través de los muros es difícil de combartir, pero puede paliarse si la superficie susceptible de humedecerse queda oculta por los azulejos sin impedir que el agua tenga vías de salida hacia el exterior ${ }^{1}$.

Tal vez por ello los ejemplares más antiguos tengan una sección trapezoidal muy acusada, creándose una cuña o embudo por donde se canaliza la humedad hacia el exterior a través de las ranuras que actúan como zona de ventilación de la pared.

Desde una forma acusadamente trapezoidal la evolución se produce lentamente hacia piezas menos gruesas, de paredes casi paralelas, cayendo en desuso el tipo anterior sobre todo al imponerse las técnicas de fabricación industrial.

\section{GENERALIDADES EN TORNO A LOS AZULEJOS PLANOS DEL ÁREA TOLEDANA}

La llegada a Sevilla de Francisco Niculoso a finales del siglo xv, es el punto de arranque en la renovación del panorama azulejero peninsular,

- Agradecemos esta sugerencia, que compartimos plenamente, al arquitecto restaurador del Museo del Greco, don Ignacio Gárate. 
profundamente enraizado en la tradición hispanomusulmana. Desde su taller de Triana se extenderá un nuevo estilo y una nueva técnica dando al soporte de arcilla el mismo tratamiento que a una superficie pictórica decorada con un amplio colorido denominado paleta de gran fuego, a base de motivos procedentes del nuevo lenguaje renacentista italiano inicialmente, que inmediatamente se verán enriquecidos con otros procedentes del repertorio hispanomusulmán, bien conocido por los talleres locales y con las aportaciones del mundo artístico flamenco.

De este modo, primero Triana y desde la segunda mitad del siglo XVI, también Talavera y Toledo van a satisfacer ampliamente la fuerte demanda que estas piezas generan en el mercado peninsular tanto desde ámbitos civiles como religiosos. Dentro de la zona toledana quedan al margen de estas corrientes renovadoras los alfares de Puente del Arzobispo, tal vez, como ha apuntado Natacha Seseña, porque se dedicaron exclusivamente a la fabricación de loza y porque hasta el siglo XVIII no poseerán un estilo decorativo propio, distinto del talaverano con cuyas producciones van a coincidir hasta ese momento, tal y como ha quedado puesto de relieve tras las excavaciones realizadas por Llubiá en la zona.

La fabricación de azulejos pintados se abordará sobre todo en Talavera, pero también en la ciudad de Toledo extremo sobre el que las fuentes documentales nos informan cumplidamente. Así, Juan Alvarez es un desconocido alfarero rescatado del anonimato por haberse seguido un proceso inquisitorial contra él en 1546 y 1547, tras el que se le condena por apostasía. Aparece citado en el documento en calidad de pintor de azulejos vecino de Toledo, que vive en el barrio nuevo ${ }^{2}$. Mucho más conocidos en su tiempo fueron los autores de las obras de mayor envergadura salidas de los talleres talaveranos o toledanos en esta segunda mitad del siglo. Juan Flores o Jan Floris, llegó a ser nombrado por el rey Felipe II en 1563, su criado en calidad de maestro de hacer azulejos, tras lo cual fija su residencia en Talavera desde donde intervendrá en la decoración de los palacios y residencias reales como el Alcázar madrileño del que sabemos que el aposento real se chapó con azulejos de Talavera y en su solería se emplearon ladrillos de Toledo ${ }^{3}$. Fue el introductor de los motivos de "ferroneries" muy difundidos en el repertorio renacentista flamenco y que alcanzarán una gran popularidad en la azulejería peninsular.

2 Escriva de Romani, M., Cerámica de la ciudad de Toledo. Estudios preliminares. Madrid 1935, págs. 27-28. Notas a pie de página.

${ }^{3}$ Martinez Caviro, B., "Azulejos talaveranos del siglo xvl”, Archivo Español de Arte, 175. Madrid 1971, pág. 286. 
El zócalo de la Generalidad de Valencia está firmado por Oliva, seguramente Juan, otro gran artista del que sabemos que una vez aprendido el oficio en Talavera, se trasladó a trabajar a Toledo en el año 1570. Pero la obra de mayor envergadura, es sin lugar a dudas, el encargo realizado en 1570 a Juan Fernández, vecino de Talavera según se especifica en el contrato, para que decorase el Escorial con azulejos azul y blanco de florón principal y de florín arabesco ${ }^{4}$.

Parece, por tanto, que pretender aislar las producciones salidas de los talleres toledanos de las procedentes de alfares talaveranos queriendo identificar elementos que personalicen a cada una de ellas, no responde a la realidad histórico-artística que nos muestra la documentación. Talavera es el motor que impulsa la formación técnica y artística de los artífices de azulejos planos de tipo talaverano, forjándose allí una interpretación artística de los temas abordados, específica de estas producciones. Una vez aprendido el oficio, muchos de ellos trasladarán su taller a la ciudad de Toledo donde siguen trabajando al modo talaverano, de ahí que la radicación del alfar carezca de la importancia artística que se le ha querido dar. Las producciones azulejeras talaveranas que mayor acogida van a tener serán las realizadas en azul y blanco y en concreto, el tema del florón principal y el florín arabesco va a repetirse en numerosos frisos de la segunda mitad del xVI. Martínez Caviró lo identifica con los motivos vegetales que en dos versiones aparecen repetidos en los chapados del monasterio escurialense ${ }^{5}$, salidos de los talleres de Juan Fernández y que también están presentes en la colección de la Casa y Museo del Greco, que presentamos en este trabajo. Junto a esta vertiente culta de la azulejería local, que concibe la representación del modelo con gran fidelidad y naturalismo, vamos a encontrar otra en la que la ejecución es más esquemática y geometrizada y se amplía el colorido incorporando el negro, ocre o naranja y el verde. Ya desde estos primeros momentos queda fijada la temática y las dos formas de abordarla que van a caracterizar las obras de tipo talaverano, hasta que en el siglo XVIII entren en una larga fase de decadencia, que se prolongará durante la centuria siguiente, reorientándose la fabricación hacia la elaboración de placas conmemorativas y sepulcrales o pequeños cuadros de azulejos de carácter religioso y votivo, todo ello marcadamente popular.

${ }^{4}$ Martinez Caviro, B., op. cit., pág. 288.

${ }_{5}^{5}$ Martinez Caviró, B., op. cit., págs. 291-292. 


\section{ORIGEN DE LA COLECCIÓN DE AZULEJOS PLANOS DE LA CASA Y MUSEO DEL GRECO}

Esta colección que aquí presentamos, ha cobrado entidad como tal fondo museístico recientemente, a raíz de nuestra labor de investigación realizada entre los restos de azulejería moderna apilados en los sótanos del zaguán del edificio conocido como Casa del Greco. Con la colabocación del personal del museo, seleccionamos, clasificamos y ordenamos el conjunto, aislando las piezas antiguas para posteriormente reagruparlas según la técnica decorativa. El resultado fue que también aquí están presentes las tres maneras tradicionales seguidas en la decoración de azulejos, es decir, la técnica de cuerda seca, cuenca y arista y la pictórica, propia del azulejo plano grupo del que nos ocuparemos en adelante.

Cuestión ineludible es la procedencia de estos materiales, que no ingresaron en el Museo por los procedimientos habituales en una entidad de este tipo que ve aumentar sus fondos generalmente mediante compras, depósitos, donaciones y en menor medida permutas. Los sótanos de la Casa del Greco, sirvieron de almacén a los restos azulejeros que, procedentes de alguna construcción del entorno, fueran susceptibles de reutilizarse, recuperando así su función primaria, devuelta a numerosas piezas reaprovechadas en la restauración recientemente acometida en el edificio del Museo. La consulta de los archivos del Centro arrojaría alguna luz sobre el edificio al que pertenecieron, pero como hasta ahora no ha sido posible acceder a ellos, vamos a recurrir al análisis del complejo constructivo integrante de la Casa y Museo del Greco para avanzar hacia la identificación del edificio que pudo estar decorado con estos azulejos planos pintados polícromos al estilo renacentista.

El conjunto de edificios del museo se levantan en la antigua judería toledana, alli donde el legendario tesorero del rey Pedro l el Cruel, Samuel Ha-Leví, erigió en 1360 una sinagoga privada, la del Tránsito, a cuyo alrededor se dispondrían otras edificaciones particulares como su palacio, baños, casas de la servidumbre, caballerizas, almacenes, etc., algunas de las cuales han sido rescatadas recientemente del olvido ${ }^{6}$. La caída en desgracia de tan relevante personaje supuso la pérdida de sus bienes parte de los cuales llegaron posteriormente a manos de la Duquesa Vieja y del Marqués de Villena en cuyas casas principales se levantan

${ }^{6}$ Lopez Álvarez, A. M. y Palomero Plaza, S., "Descubrimiento de un probable baño ritual judio junto a la sinagoga de El Tránsito (Toledo)», Sefarad. Madrid 1989, fasc. 2, págs 395-396. 


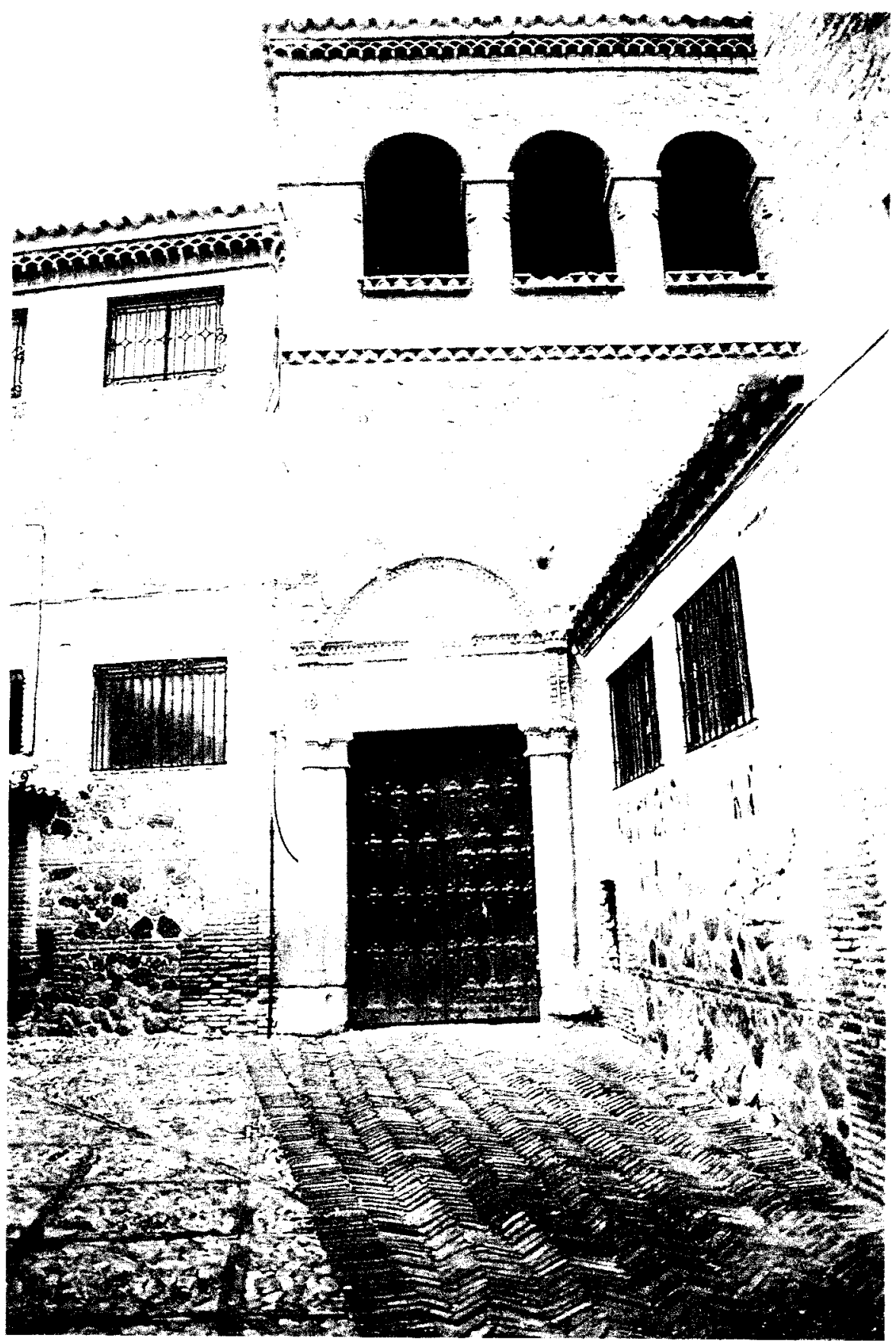

Fig. 1. Acceso al Museo del Greco. 
los actuales edificios de la Casa y Museo del Greco (fig. 1), adscripción ésta criticada desde sus comienzos ${ }^{7}$. El edificio conocido como Casa del Greco, sería la vivienda de un propietario acomodado, construida en el siglo XVI, haciendo concesiones tanto a la tradición popular toledana como al estilo múdejar y en menor medida al Renacimiento italiano. Posee una perfecta unidad constructiva y ornamental y su planta cuadrada irregular reproduce la de los sótanos localizados bajo ella, cronológicamente anteriores, ya que tuvieron que ser reforzados con sucesivos arcos en torno al pilar central que soportaba el peso de la cubierta de esta estancia, para asi recibir las nuevas cargas. La decoración del edificio se inscribe sobre todo en la tradición mudéjar, latente en el Toledo de ese siglo, siendo muy puntuales las referencias a las nuevas corrientes renacentistas, mejor implantadas en los grandes edificios civiles y religiosos que en estos otros enraizados en una vertiente local muy acusada como se pone de manifiesto también en su azulejeria que utiliza para los suelos, junto al ladrilo bizcochado, olambrillas de cuerda seca, mientras que en los muros predomina la cuenca y arista. En ningún caso se emplea el azulejo plano cuya generalización en la zona se produjo en la segunda mitad del XVI, cuando la Casa ya estaría en pie. Los subterráneos bajo los jardines de la Casa, son otro gran resto constructivo nada despreciable que oculta numerosas incógnitas bajo sus tres plantas a la espera de ser adecuadamente investigadas. Las características de este espacio le convirtieron en blanco de la fabulación popular, creyéndose que en ellos guardaba sus tesoros Samuel Ha-Leví y que allí, el Marqués de Villena realizaba prácticas de magia y nigromancia. Estas estructuras subterráneas nunca recibirian este tipo de ornamentación, reservada a aquellas otras áreas de habitación permanente.

Finalmente, integra el actual complejo museístico un tercer edificio concebido por el Marqués de Vega-Inclán como Museo del Greco, de ahí que para posibilitar su creación, hiciese reedificar un antiguo palacio del Renacimiento "que exigía inmediata demolición por su ruinoso estado, así como el de sus artesonados y preciosos restos" ". Sería a raíz de las obras de reconstrucción cuando se extranjeron de su interior los azulejos pintados que estudiamos, mínima representación de cuantos decoraron sus estancias hasta el momento en que se abandonó.

7 San Roman, F. DE, El Greco en Toledo. Toledo 1910, págs. 95-110. Considera que el emplazamiento de las casas del Marqués de Villena estabá desplazado más hacia el rio, en el actual Paseo del Tránsito, correspondiendo los solares de la Casa y Museo al grupo de edificios propiedad de la Duquesa Vieja o Duquesa de Arjona.

${ }^{8}$ Beruete, A. DE, y El CONDE de Cedillo, Catálogo del Museo del Greco de Toledo. Madrid 1912, págs. 3-4. Incluye dos planos de la planta baja y de la principal que lo muestran en obras. 


\section{ESTUDIO}

Los azulejos pintados polícromos que componen la colección de la Casa y Museo del Greco, son en su mayoria piezas cuadradas de $13 \times 13$ cms o de $9 \times 9$ las olambrillas, oscilando su grosor entre 1,5 y $2 \mathrm{cms}$. Asímismo, cuenta el conjunto con varios alizares y piezas rectangulares, algunas para contrahuellas. Los temas predominantes son los vegetales, florales sobre todo, a menudo fuertemente geometrizados, sin faltar los figurativos tanto zoomorfos como antropomorfos, quedando conformado asi un conjunto muy representativo de la azulejería toledana. Buen número de los ejemplares inventariados ocupaban una posición secundaria en el panel que enmarcaban, sirviendo de cenefa o remate. Aún así, hemos podido recuperar algunas composiciones y detectar otras, a veces, a partir de un único ejemplar como el $386 / 3^{9}$ (figs. 2 y 3 ) vestigio

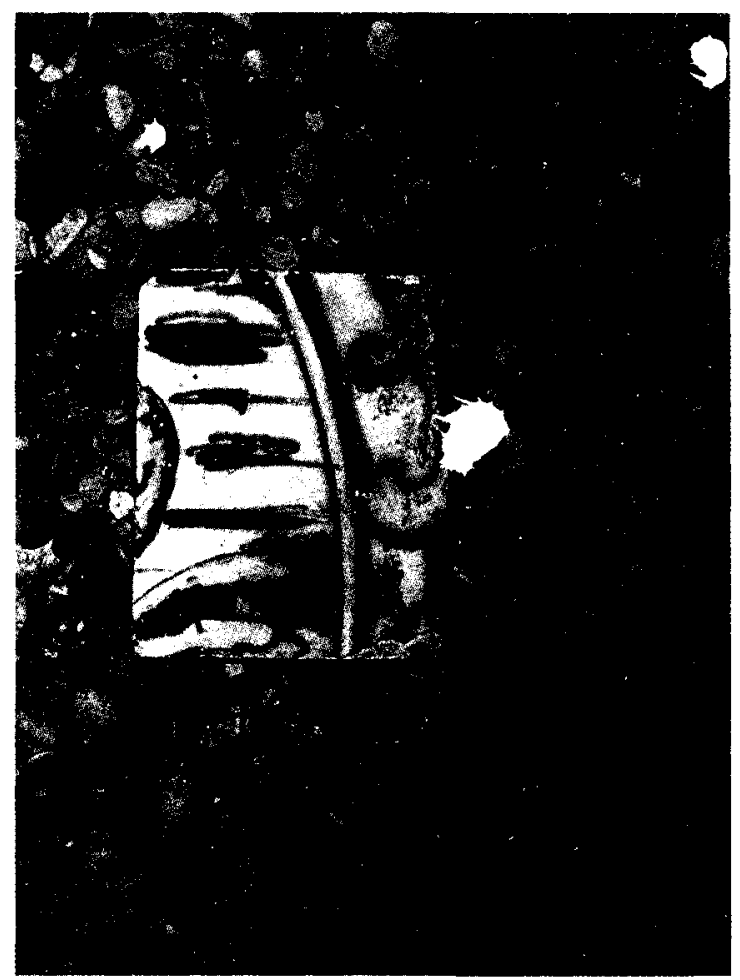

Fig. 2. Azulejo núm. 386/3. Tema heráldico.

${ }^{9}$ Esta numeración que utilizaremos en adelante, corresponde al número de inventario general que hemos dado a la pieza en el museo. 


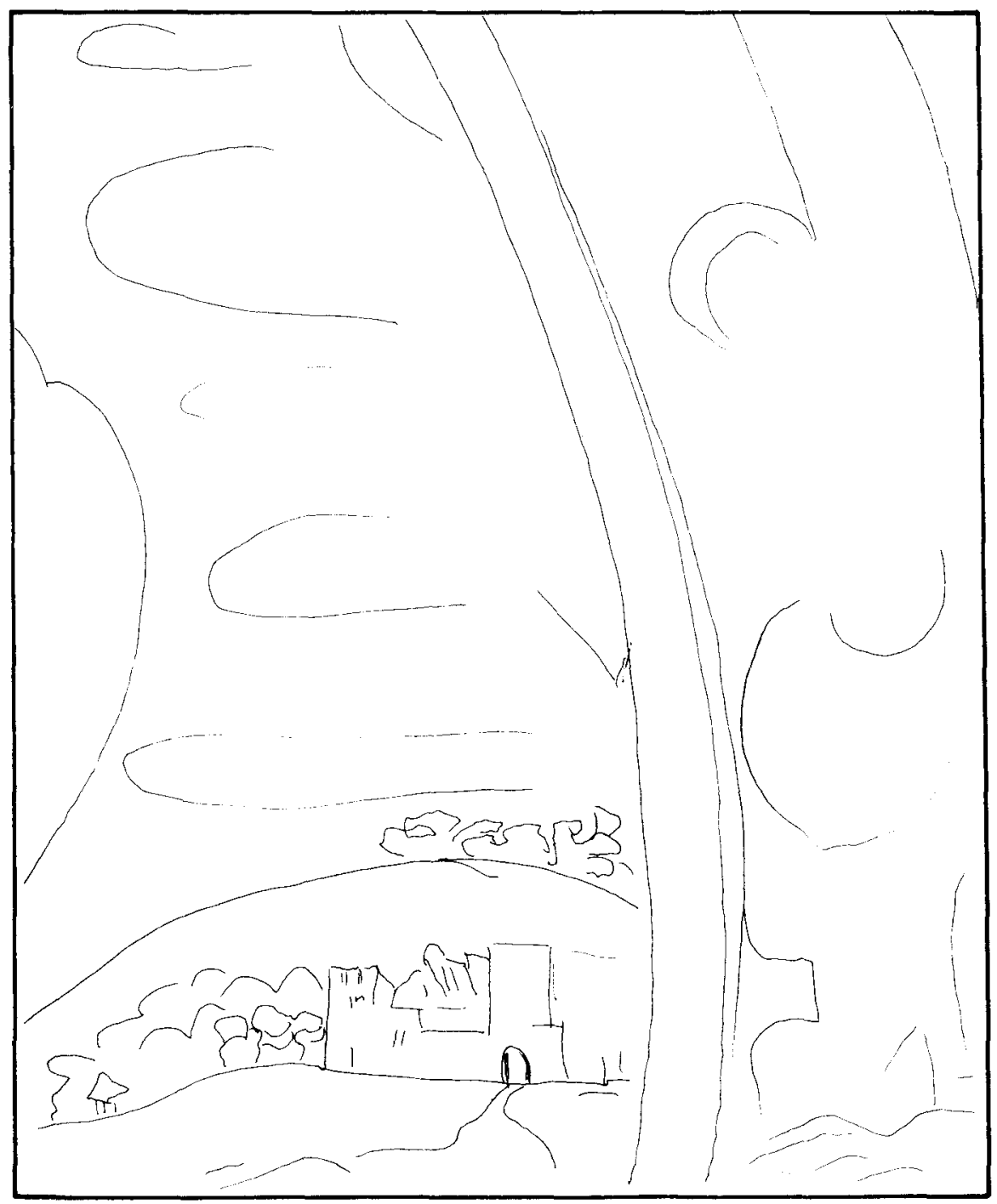

Fig. 3. Dibujo de la pieza anterior. 
de un conjunto posiblemente de carácter heráldico del que resta este paisaje de castillo sobre colina y parte del lambrequín. El resto de los paneles responden a composiciones florales, obtenidas repitiendo indefinidamente los motivos de cada pieza como constatamos en el 373 (figs. 4 y 5) cuyo tema está presente también en diversos forrados de la Ermita de la Virgen del Prado (Talavera) realizados en torno al año 1636. Menos frecuentes son otros conjuntos como el 372 (fig. 6) o aquél del que formó parte la pieza 390 (fig. 7) también seleccionado para decorar el zócalo del convento de Carmelitas Descalzos (Toledo). Otros dos únicos ejemplares (387) (fig. 7) nos recuerdan la estrecha vinculación que existe entre algunos cartones de azulejos y los de tejidos, brocados en este caso. Esta composición guarda estrechos paralelismos con el frontal del altar de Lanzahita o con la iglesia de Mombeltrán (Ávila).

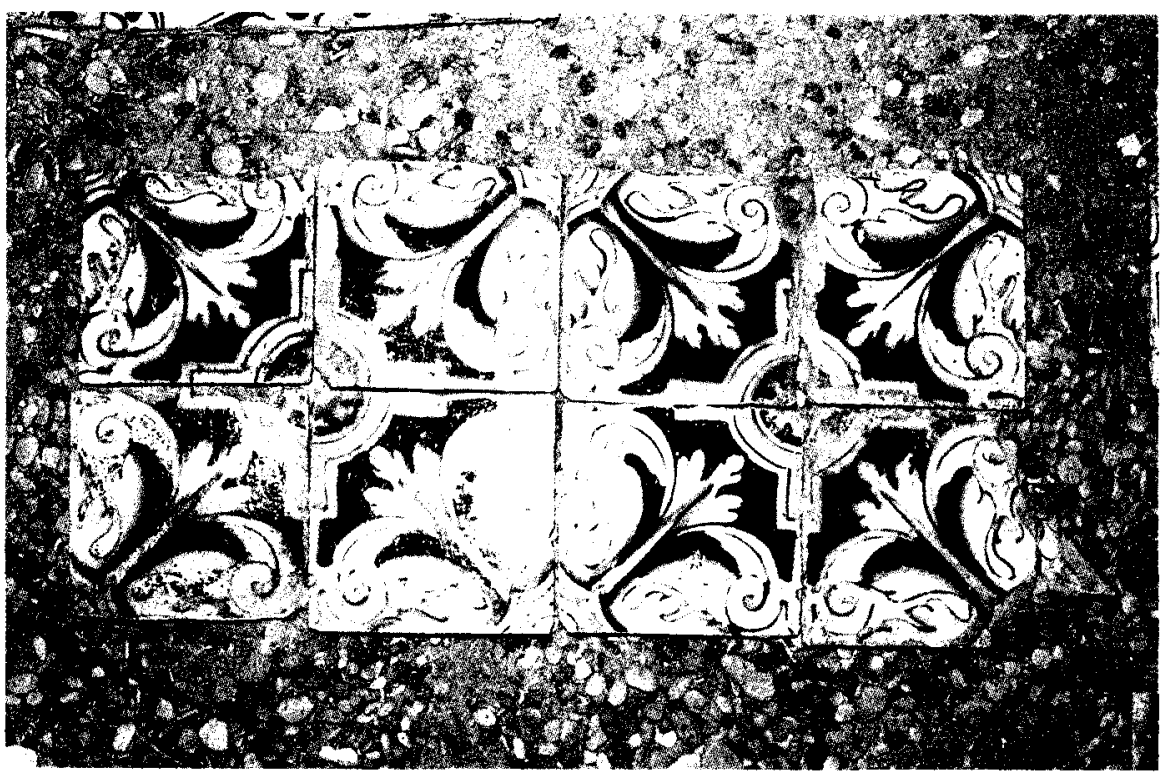

Fig. 4. Panel núm. 373.

Están mejor representados en la colección otros temas muy divulgados, por su gran aceptación, desde su surgimiento en la segunda mitad del xvi dentro y fuera del área toledana. Así, el del florón principal y florín arabesco citado de este modo en el documento de contratación para 


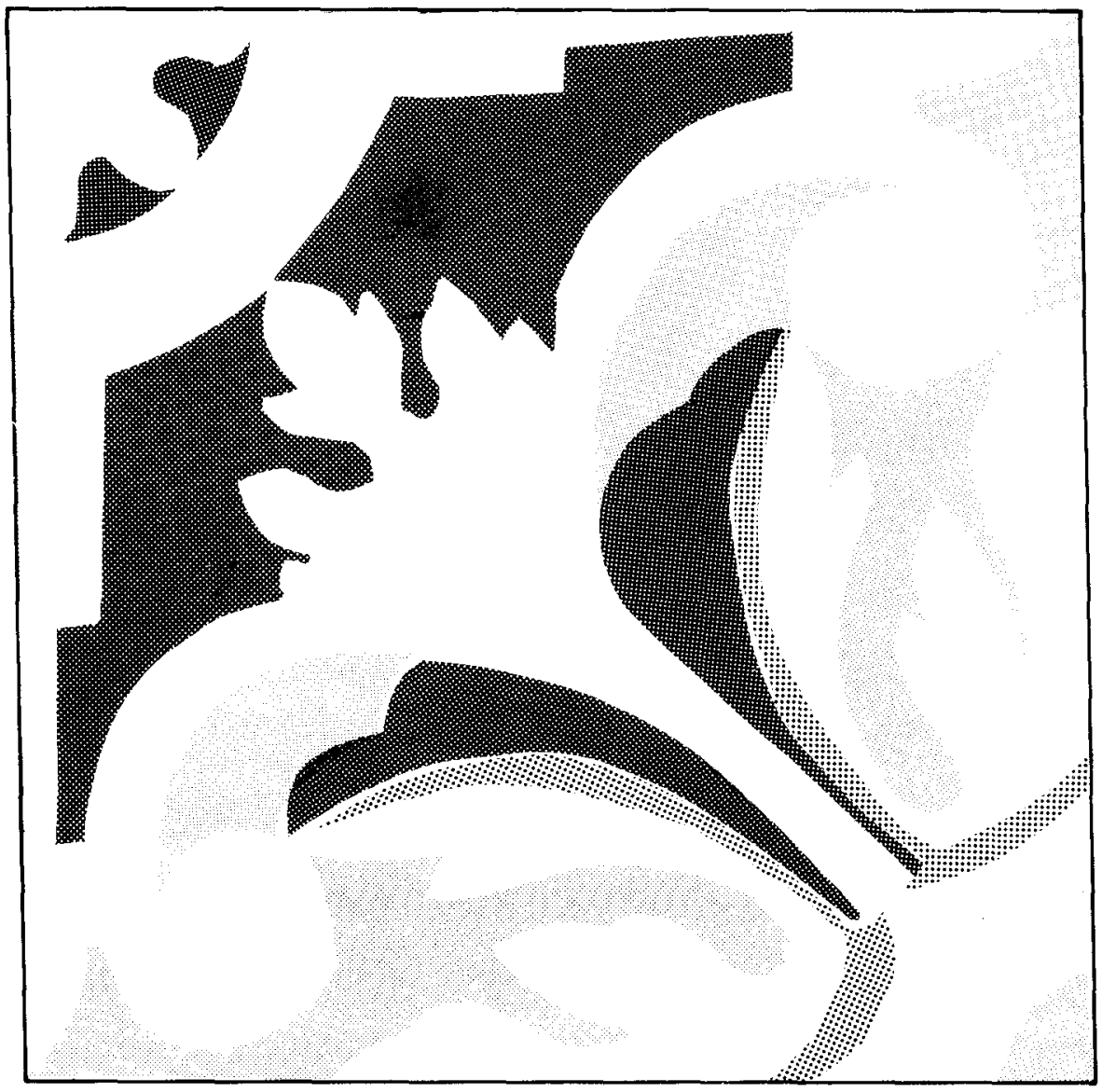

Fig. 5. Dibujo del panel anterior. 


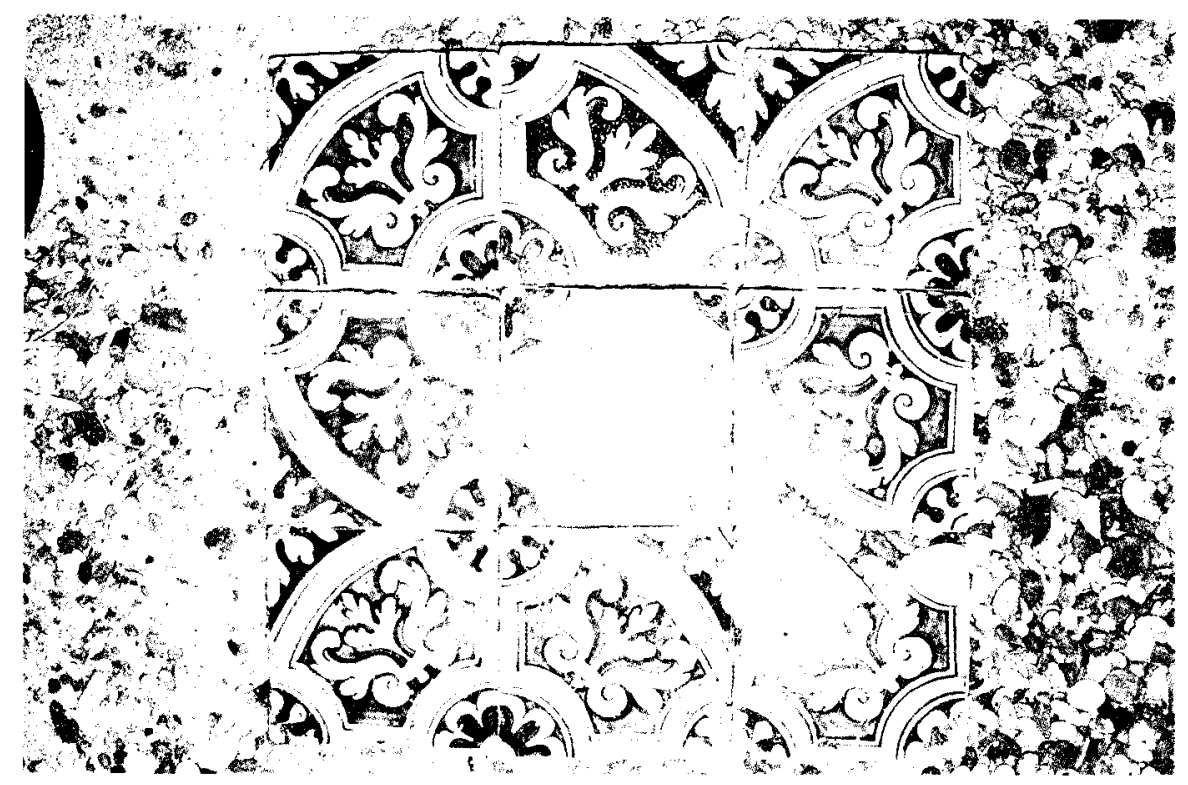

Fig. 6. Panel núm. 372.

chapar los zocales del monasterio de El Escorial, encargo efectuado a Juan Fernández en 1570 y que Martínez Caviró identifica con el representado en nuestro ejemplar 371 (figs. 8-9). Fue abordado con anterioridad, en 1567 en la iglesia toledana de Erustes y también está presente en los frontales de las madrileñas iglesias de Talamanca y de Santorcaz. El segundo tema que constatamos ampliamente en nuestro conjunto es el de clavo (fig. 10) que imita a los casetones renacentistas de madera, ofreciendo diversas variantes al adaptarse al nuevo soporte cerámico, de las que tenemos recogidas tres, la flor central en movimiento, la margarita y la estrella de ocho puntas o rosa de los vientos. Con el apoyo de algunos ejemplos podemos acercarnos a la forma de organización de esta composición que frecuentemente intercala "ferroneries" (393) como en el friso de la casa del señor Páramo en Oropesa que está rematado con una banda de azulejos conteniendo el motivo de cresta de ola evolucionada (381). Se prefieren emplear para recubrir frontales de altar como el de la ermita de Iglesuela (Toledo) o la Alcoba (Talavera) y es posible que en esta inclinacion influyera el hecho de ser el único tema no figurativo abordado por Francisco Niculoso durante su estancia en España y que lo hiciera precisamente para revestir un frontal de altar. 


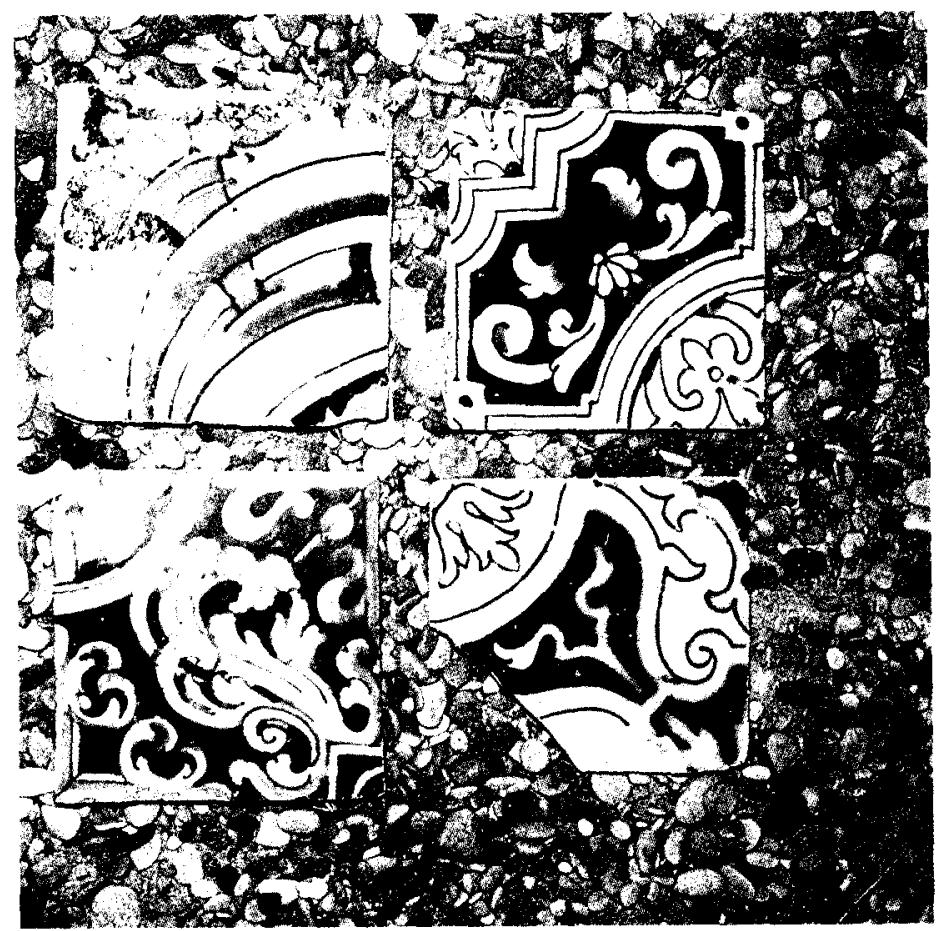

Fig. 7. Azulejo nüm. 390 (parte superior izquierda) y núm. 387/1-2 (superior e inferior derecha). 


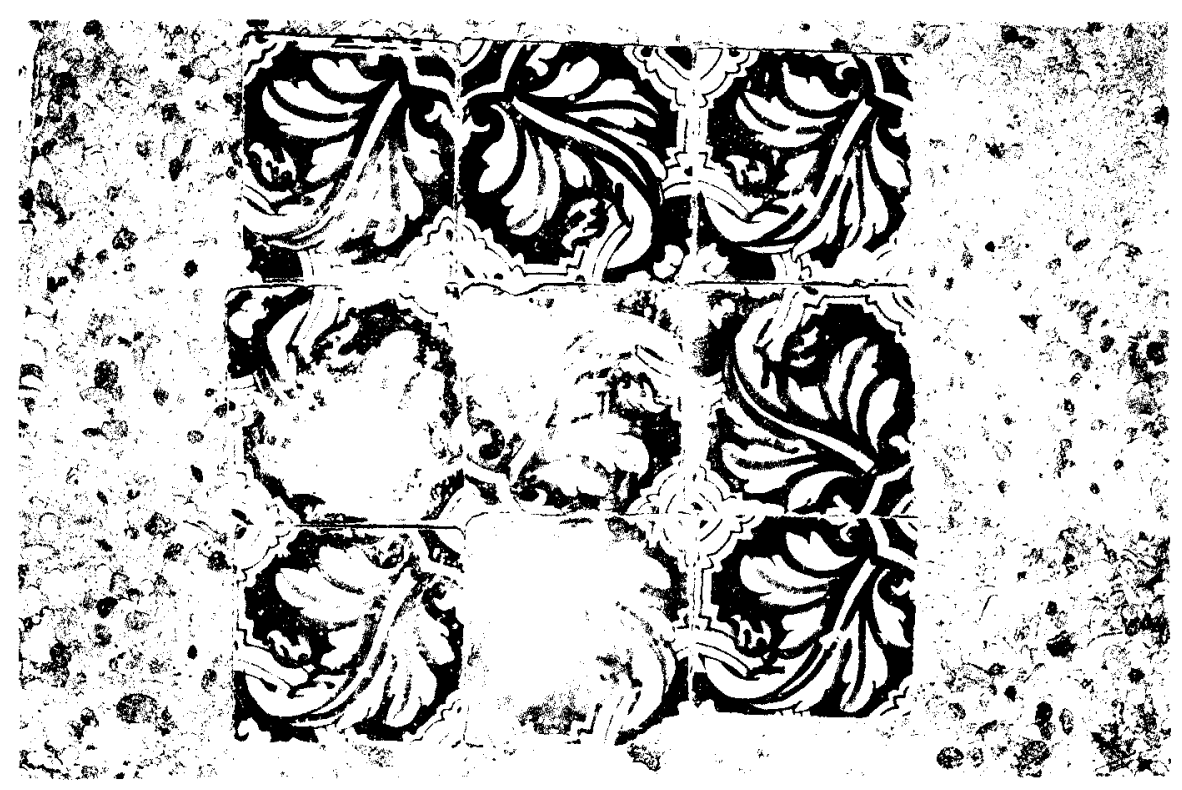

Fig. 8. Panel núm. 371. Tema del florón principal y florin arabesco.

Cabe suponer que su difusión estuvo impulsada desde los alfares trianeros y en concreto, la introducción en Levante está ligada a la llegada de artífices sevillanos para decorar la iglesia del Corpus Christi tras haberse adquirido en esa localidad un elevado número de piezas ${ }^{10}$.

El segundo grupo que hemos establecido, integrado por azulejos empleados para enmarcar o como cenefas, se presta a una mayor diversidad temática. El estilo desornamentado está aquí representado (383) (fig. 11) evidenciándose la búsqueda característica de un efecto arquitectónico de raíz herreriana, imitando mármoles mediante un jaspeado polícromo también presente en el interior de las tarjetas de la serie de "ferroneries" (394) y que creemos debe relacionarse con la loza «jaspeada y esponjada", elaborada por el sevillano Jerónimo Montero para el monasterio escurialense el último cuarto del siglo XVI.

Las "ferroneries» $(392,393,394)$ (fig. 12) son una serie introducida en la Península por Juan Flores, artista originario de Amberes, que se inspira en las labores de hierro forjado recreadas con motivos italoflamen-

${ }^{10}$ Catálogo del Museo Nacional de Cerámica y Artes Suntuarias González Marti. Madrid 1985, pág. 17. 


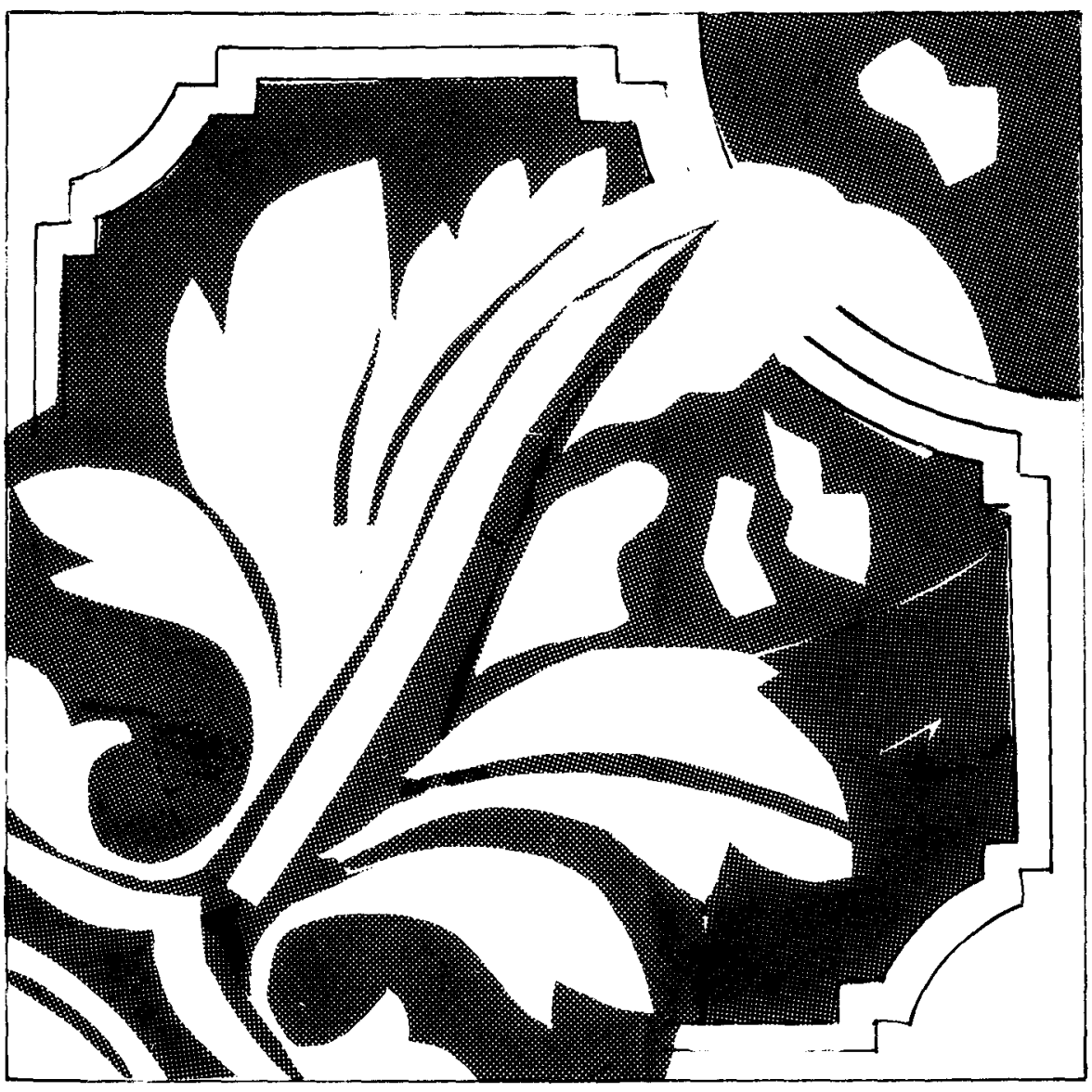

Fig. 9. Dibujo del panel 371. 


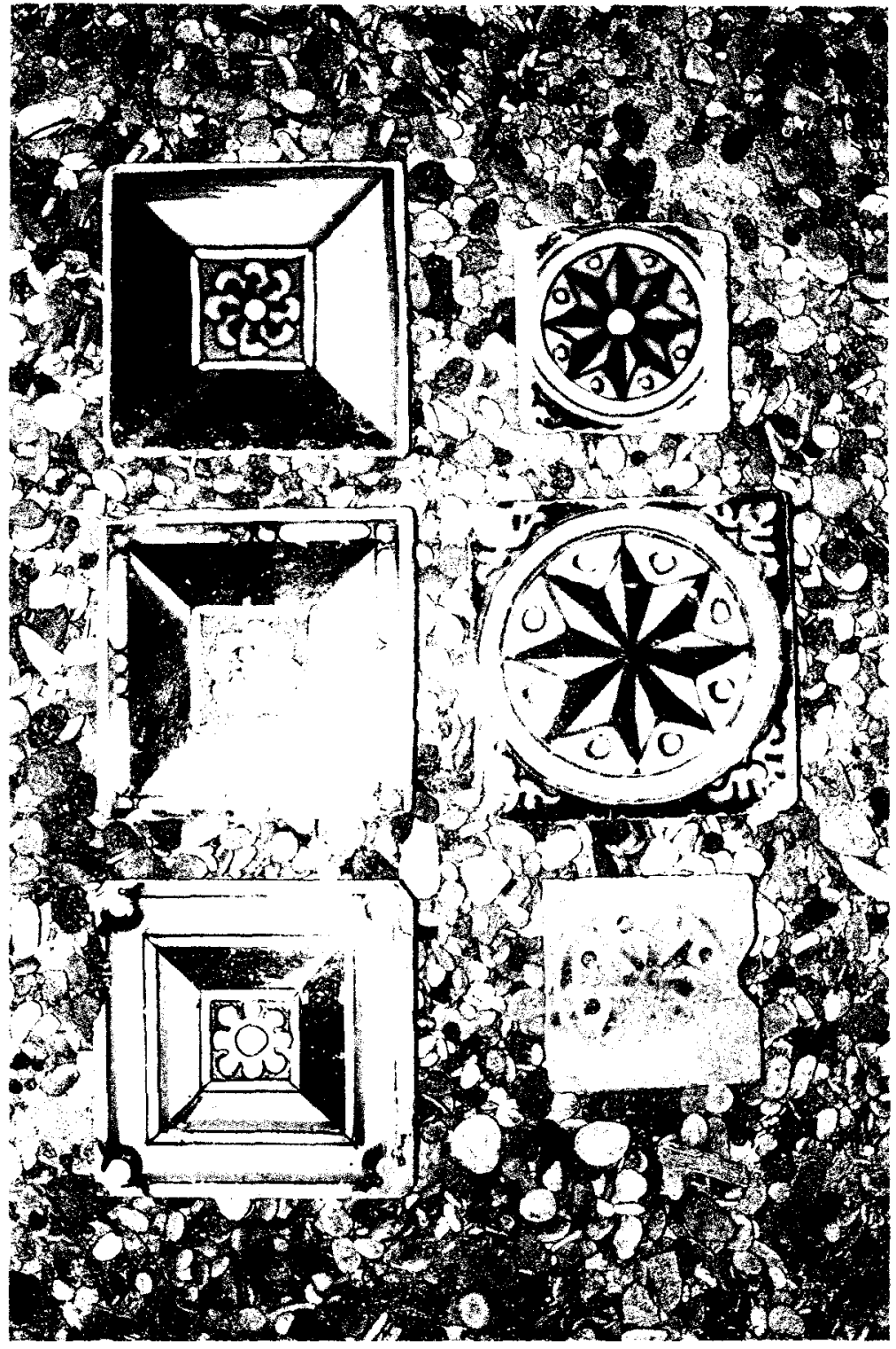

Fig. 10. Tres azulejos "de clavo" (a la izquierda) y otros tres "tipo Delft" (a la derecha). 


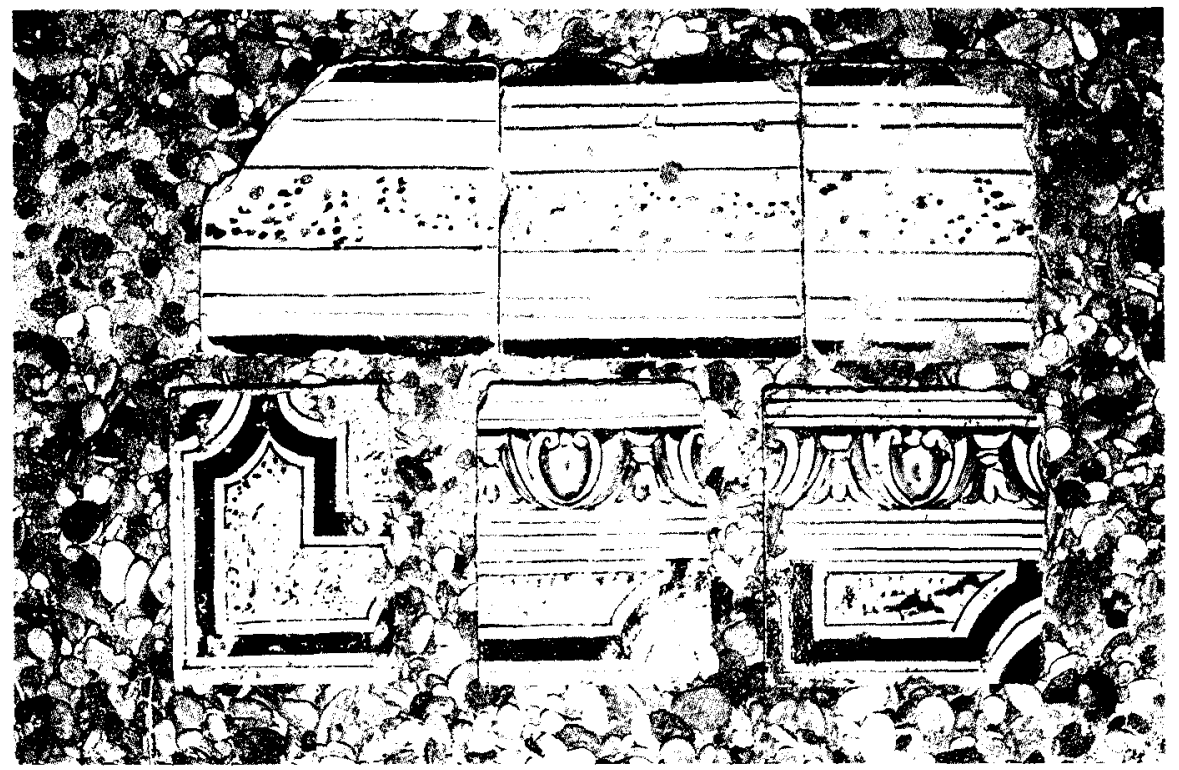

Fig. 11. Varios exponentes del estilo desornamentado.

cos a base de tarjetas, volutas y orificios para remaches. Alcanza tanto éxito, que sus ecos perduran en los diseños azulejeros toledanos hasta este siglo, como atestiguan las trazas de una placa (368) indicadora de la plaza del Greco realizada en abril de 1914 según modelo de don Sebastián Aguado, en la Escuela de Artes y Oficios para conmemorar con su colocación y con el levantamiento de un monumento en el vecino Paseo del Tránsito, el tercer centenario de la muerte del artista ${ }^{11}$ (fig. 13).

También conocieron gran difusión los azulejos tipo Delft que recogen las influencias de la porcelana china y sus imitaciones, extendidas por Europa desde los Países Bajos. Esta decoración de temas independientes ejecutados a pincel se imita en la Península desde el siglo $\times \mathrm{VII}^{12}$. Entre los motivos preferidos nos interesan resaltar los de cetrería y los florales, presentes en dos piezas de los fondos del museo $(399,400)$

"Marques de Vega-InCLAN, El, Ampliación del catálogo del Museo del Greco y noticia de las obras ejecutadas hasta la fecha por el Patronato. Diciembre, 1914, págs. 22-23.

12 Pleguezuelo, A., Azulejo sevillano. Sevilla 1989, pág. 57. 


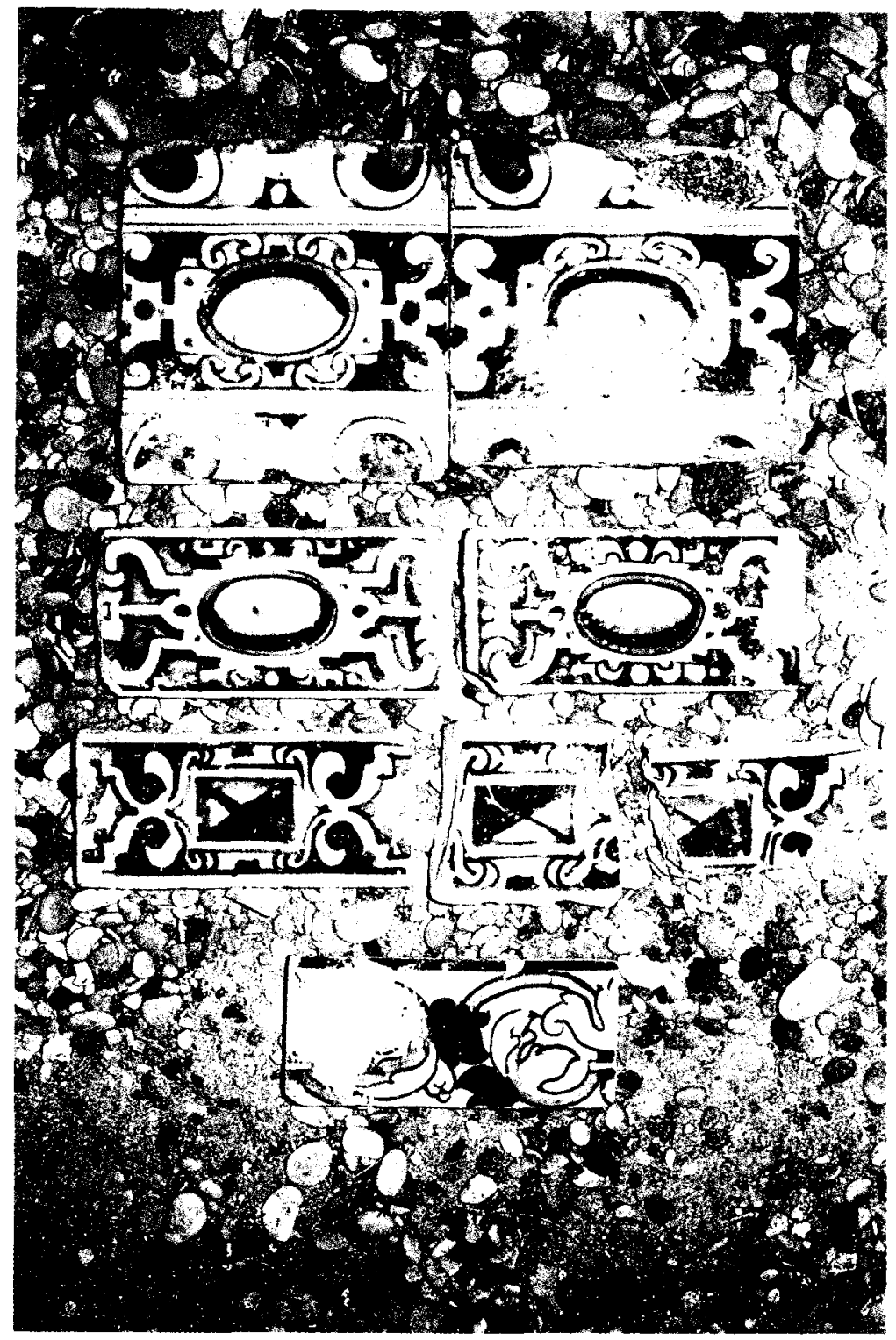

Fig. 12. Decoración de "ferroneries". Excepto la pieza inferior que es de tema floral. 


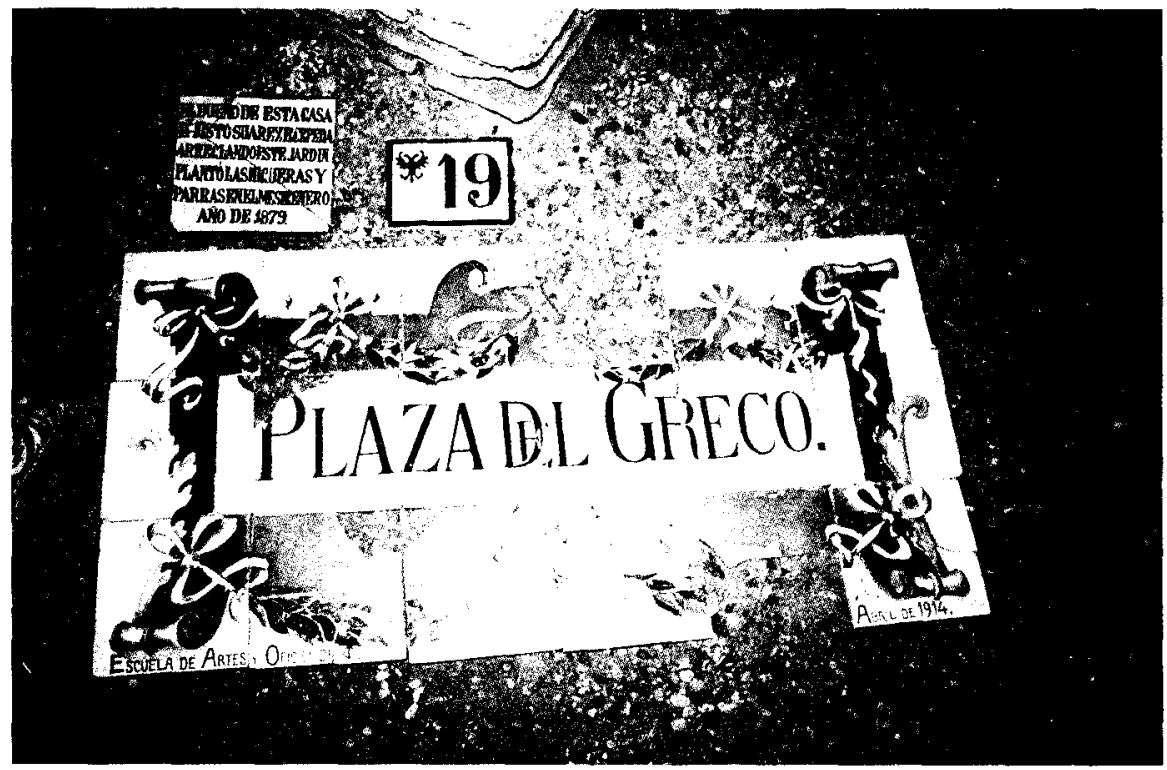

Fig. 13. Placa de 1914 que identificó un lugar público.

representando un perro en marcha y una flor de tonos verdosos (fig. 14), lo que unido al tipo de pasta de las piezas, nos están recordando a las producciones salidas de los alfares sevillanos. Los que, sin duda, tienen origen local son los azulejos de este grupo decorados con estrella de ocho puntas según el esquema descrito $(401,402,408)$ (fig. 10).

En esta colección toledana ha quedado, asimismo, buena muestra de los motivos de cenefas en circulación, como los festones con motivos florales sobrepuestos $(376,377)$ (fig. 15) , círculos concéntricos entrelazados con flor central (374), formas acorazonadas con volutas e interespacio marcado (375) (fig. 16), o en reserva y una flor central (384), etc. todos ellos, dentro de la diversidad, tienen en común su profunda raiz clásica, presente también en el tema del fauno desnudo (379) interpretado según dos versiones, una más popular (378) que la otra (figs. 17 y 18). Nos interesa resaltar esta doble perspectiva presente en otros motivos de la azulejería local, el de cresta de ola (380, 381) (figs. 19 y 20), lo que nos permite extraer algunas generalidades. La interpretación apegada al canon clásico es naturalista, de trazo firme, maneja el claroscuro para obtener volumen, y prefiere los colores azul y blanco únicamente o a lo sumo el amarillo. En tanto que el tratamiento más popular se concre- 

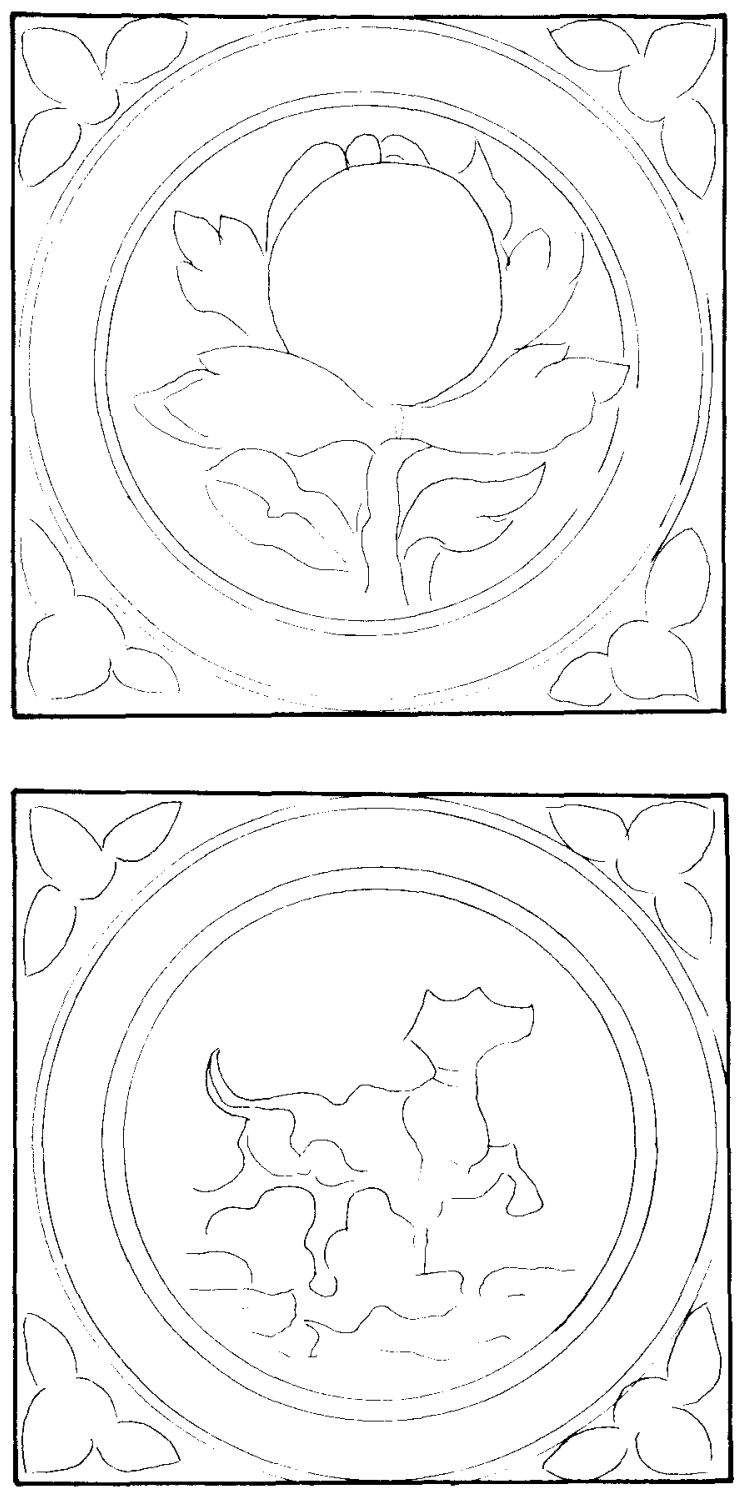

Fig. 14. Varias olambrillas "tipo Delft». 


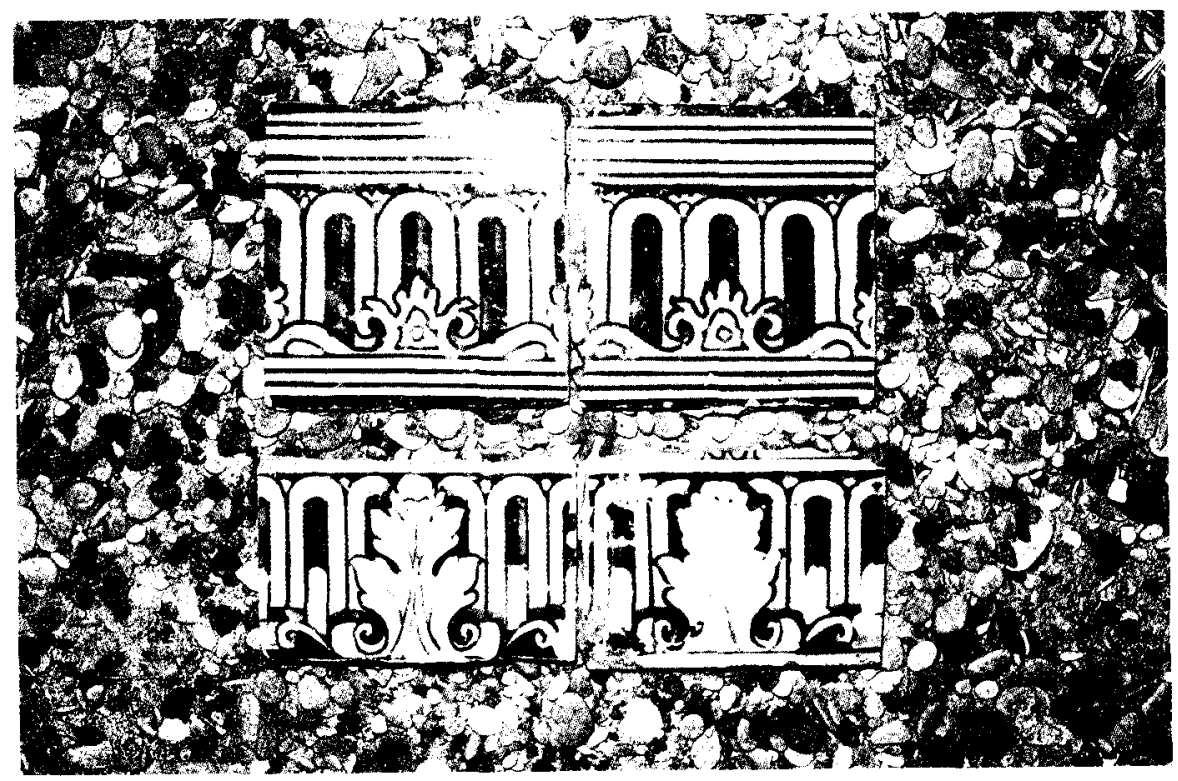

Fig. 15. Azulejos núms. 376 y 377 para cenefas.

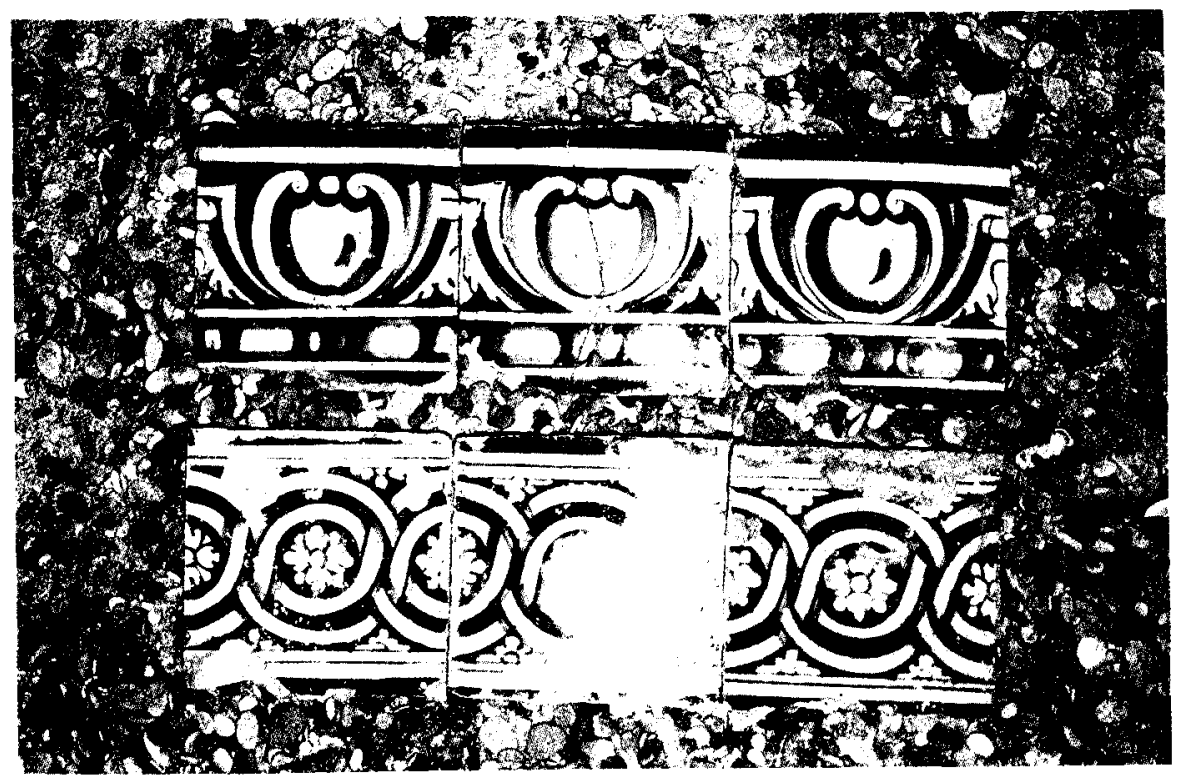

Fig. 16. Azulejos núms. 374 y 375 para cenefas. 


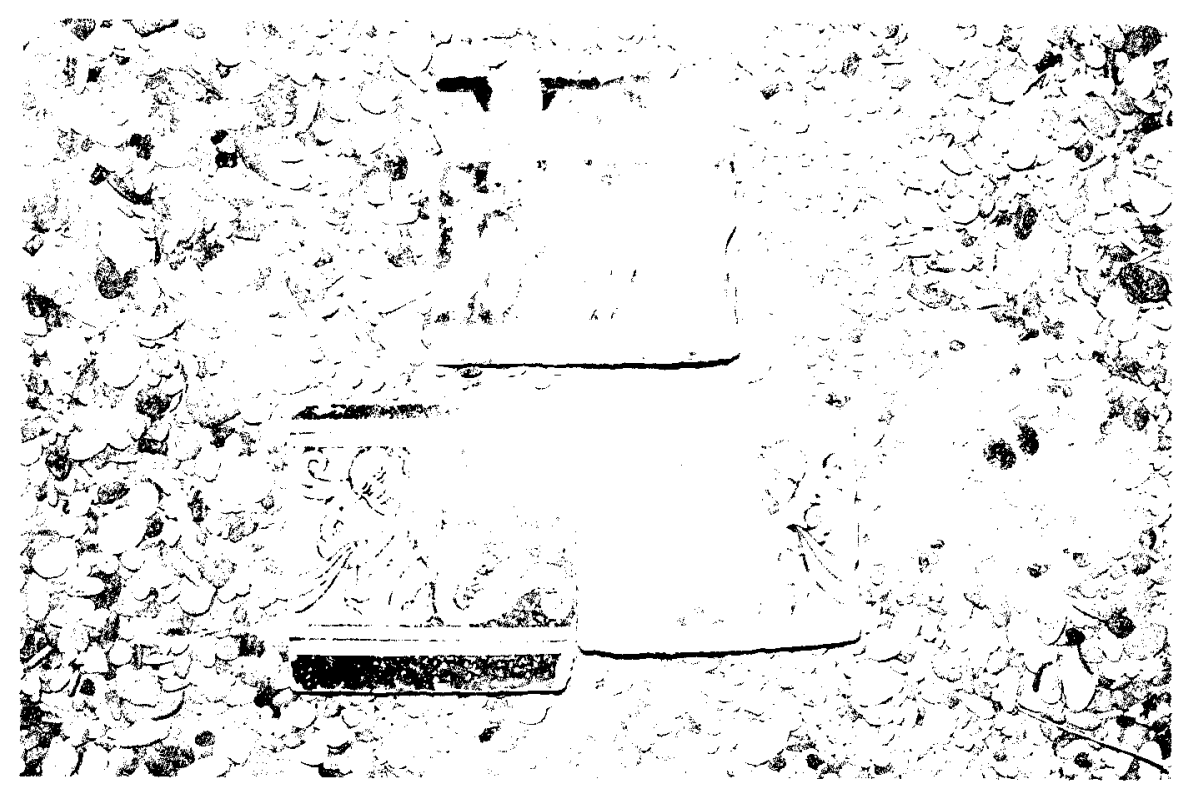

Fig. 17. Piezas decoradas con dos versiones del mismo tema del fauno desnudo.

ta en el acusado esquematismo del motivo, desinterés por el volumen y empleo de una gama cromática más amplía que incluye negro, ocre y verde, finalmente, se introduce en la composición el gusto por la asimetría, para lo cual, en nuestros ejemplares sólo se repite la línea de ovas en la banda superior del azulejo. La aparición de ambos enfoques, el más clásico y el más popular, fue simultánea y temprana constatándose ya en zócalos de la segunda mitad del XVI, que por lo tanto, nos remiten a un modelo común, abordado con diferente sensibilidad presente en el gusto de la sociedad de la época.

A partir del siglo XVII la azulejería del área talaverana va a sufrir una gran decadencia reorientándose la producción hacia obras más sencillas ${ }^{13}$. Buen exponente de esta situación es el azulejo 369 que conmemora un hecho de carácter privado de manera económica, simple y funcional (fig. 21).

13 Seseña, N., "Talavera y Puente del Arzobispo", Cerámica esmaltada española. Barcelona 1981 , págs. $75-92$. 


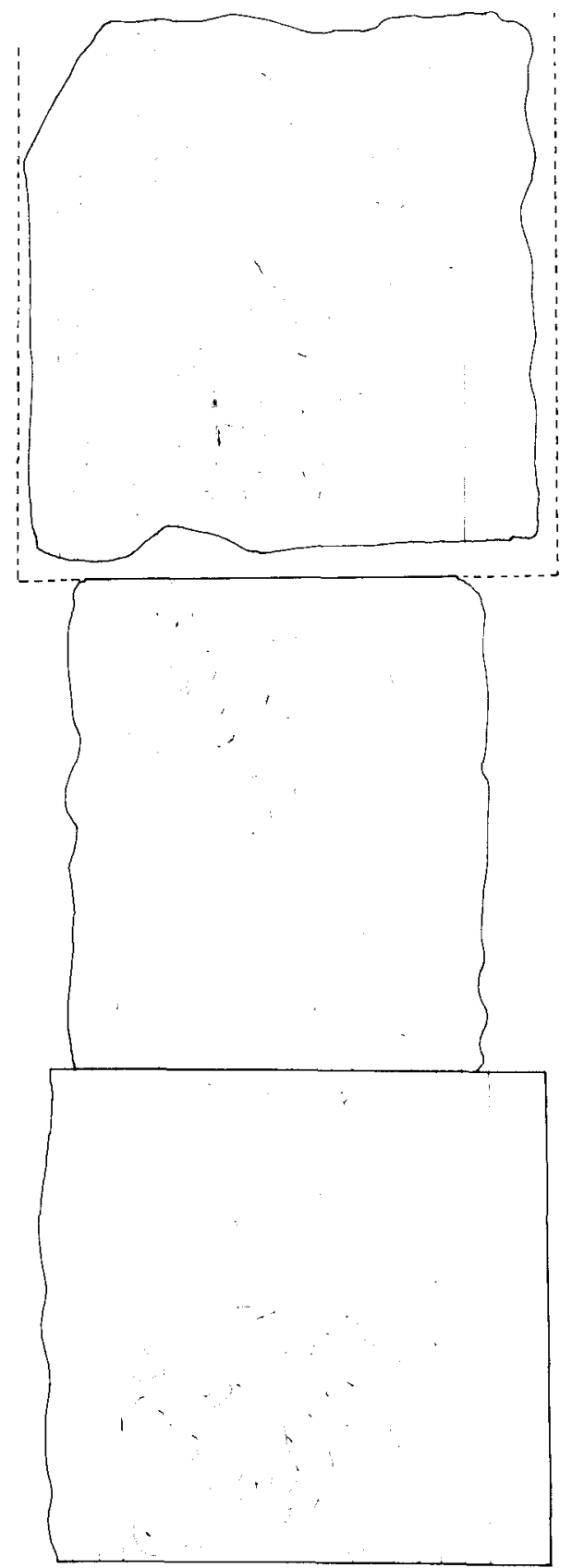

Fig. 18. Dibujos de las piezas anteriores 378 y 379 . 


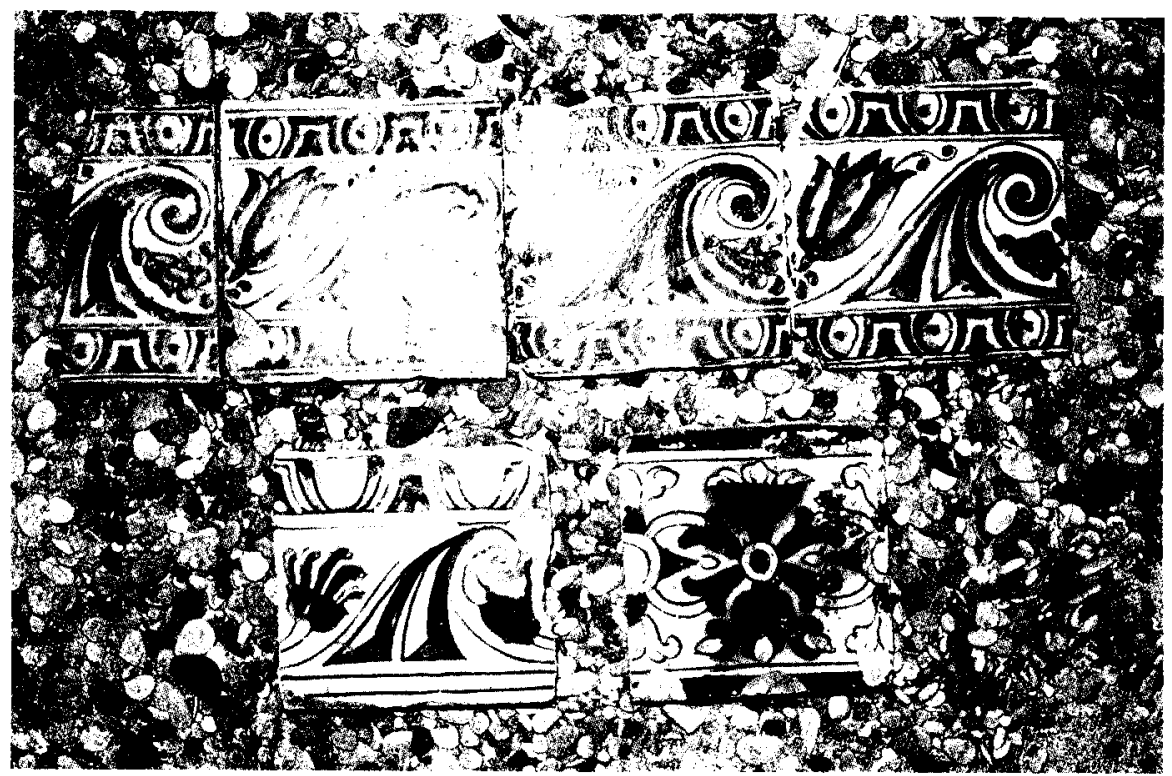

Fig. 19. Dos versiones del tema cresta de ola núms. 380 y 381

Finalmente, queremos reseñar otra pieza, al margen del conjunto visto hasta ahora, pero de gran interés por tratarse del único cuadro de devoción de la colección (280). Ignoramos su procedencia y se halla colocado en la galería alta de la Casa del Greco, a partir del momento en que se acondicionó el edificio para desempeñar su función actual. Son 15 azulejos representando a San Sebastián siguiendo una estética manierista ${ }^{14}$, que en lo popular perduraría durante el siglo XVII (fig. 22).

\section{CONCLUSIONES}

El conjunto de los materiales aquí presentados, hay que situarlo de modo general, en un periodo de tiempo comprendido entre la segunda mitad del siglo XVI y el XVII aunque existen algunas piezas claramente

14 Esta adscripción, que nos parece correcta, se la debemos a doña Angela Franco. Vaya para ella nuestra agradecimiento desde estas páginas. 

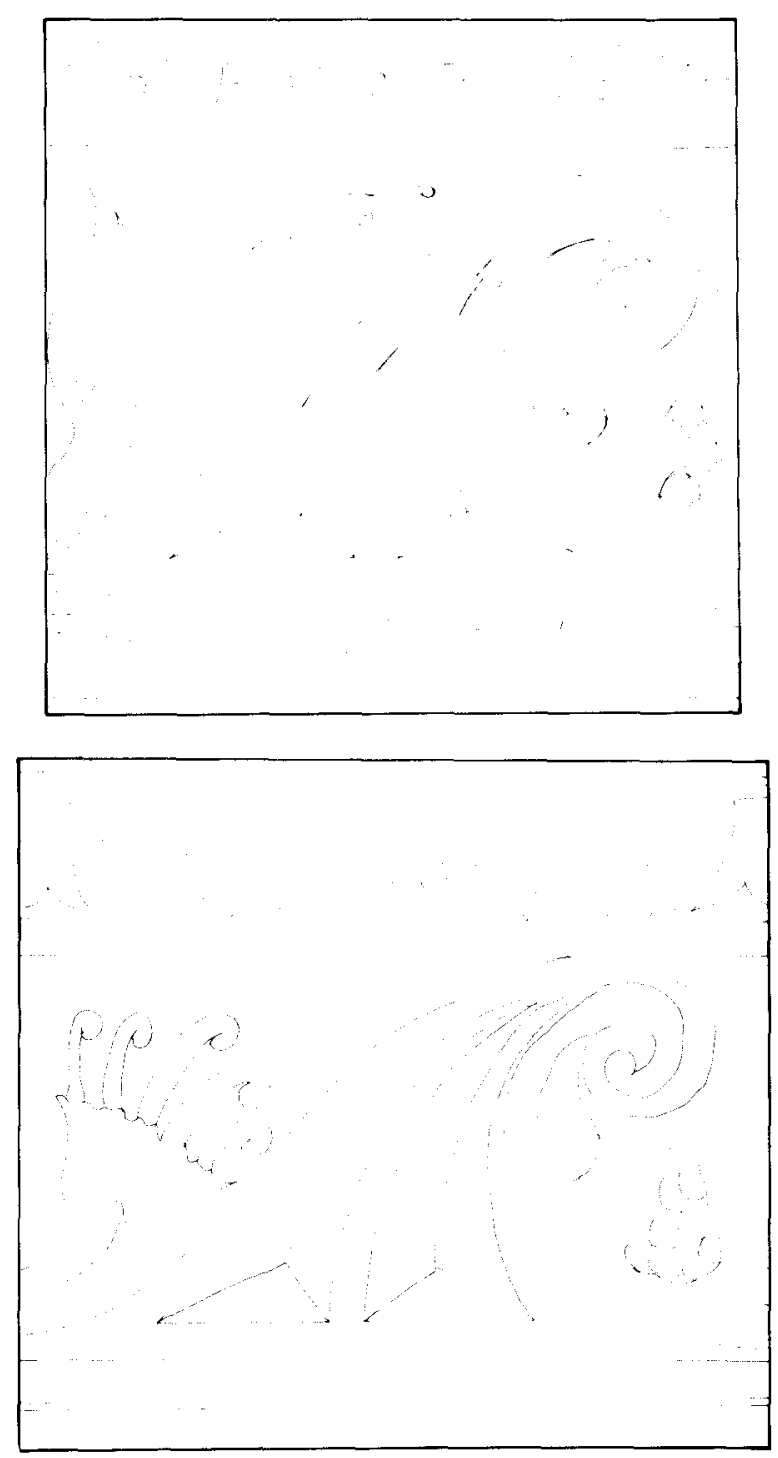

Fig. 20. Dibujos de las piezas núms. 380 y 381 . 


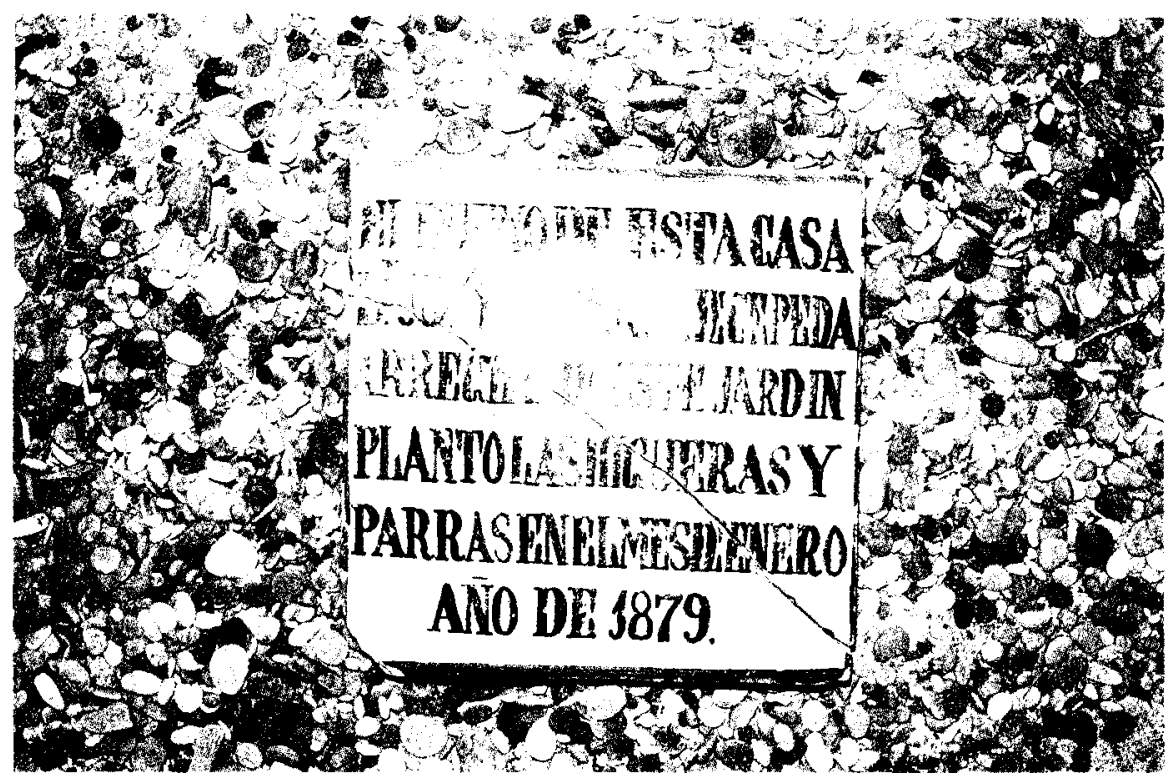

Fig. 21. Azulejo núm. 369 la pieza sirve para recordar un hecho privado.

posteriores (372) testigos de alguna remodelación parcial acometida en el edificio palaciego al que pertenecieron. Llegado el momento de señalar cronologías, carecemos de parámetros fiables que posibiliten la obtención de cierta precisión en las dataciones de la azulejería peninsular, más allá del análisis estilístico en que se basan cuando no hay apoyo documental. La búsqueda de estos indicadores es más necesaria por cuanto que el mundo estético popular evoluciona formalmente de manera lenta. Por tanto, únicamente si recurrimos al estudio global del azulejo, deteniéndonos por igual en las posibilidades del soporte y de la superficie decorada, podrá avanzarse en este sentido. El estudio de las pastas, es un campo en el que sólo se han hecho breves incursiones ${ }^{15}$ y que ofrece enormes posibilidades susceptibles de aprovechamiento con el conveniente apoyo analítico, permitiendo que nos aproximemos al conocimiento de los centros productores y posteriormente, adscribir las obras salidas de ellos.

15 Aguado señala que el barro de Talavera es más claro que el de Toledo, más ferruginoso y rojizo. Azulejeria toledana a través de los siglos. Toledo 1975, pág. 14. Sobre los barros sevillanos contamos con las observaciones de Pleguezuelo quien indica que generan pastas claras amarillentas o a lo sumo de leve matiz rosáceo, op. cit., pág. 29. 


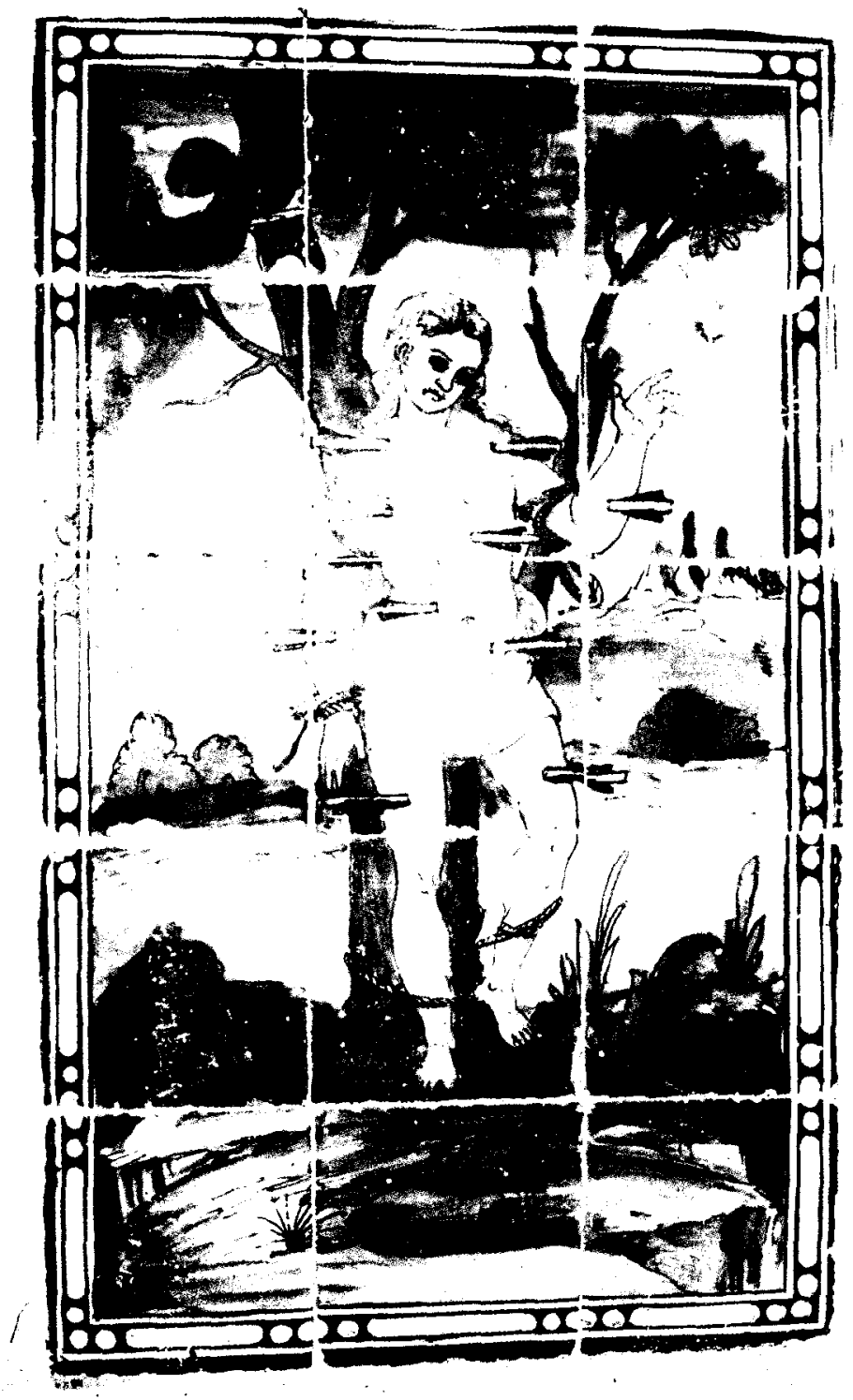

Fig. 22. Cuadro devocional representando el martirio de San Sebastian. 
